\title{
The attitude of consumers towards "Made in Italy" products. An empirical analysis among Italian customers
}

\author{
LUcio CAPPELLI \\ University of Cassino and Southern Lazio, Italy \\ cappelli@unicas.it \\ Fabrizio D'ASCENZO \\ University Sapienza of Rome, Italy \\ fabrizio.dascenzo@uniroma1.it \\ Roberto RUGGIERI \\ University Sapienza of Rome, Italy \\ roberto.ruggieri@uniroma1.it \\ Francesca ROSSETTI \\ University Sapienza of Rome, Italy \\ francesca.rossetti@uniroma.it \\ Alessandra SCALINGI \\ University Sapienza of Rome, Italy \\ alessandra.scalingi@uniroma1.it
}

\begin{abstract}
The paper is part of a broader research project studying consumer's attitude towards "Made in Italy" products through empirical investigation. The research questions addressed are: 1) Does recognition in terms of the qualitative characterization of "Made in Italy" products exist? And if so, 2) are people willing to pay, in quantitative terms, a premium price for such products? From a theoretical standpoint, the research seeks to fill a gap in the literature, since studies combining the "made in" characteristic with measured "willingness to pay" are neither conventional nor numerous. The specific purpose of this contribution is to analyze the relationship between the purchase of "Made in Italy" products, recognition of the quality and willingness to pay a premium price on the part of Italian consumers, reporting the results of an empirical research. The survey involved a total of 315 Italian consumers while three commodity sectors were analysed: food, fashion and mechanical automation. The results confirm that there is a propensity to purchase "Made in Italy" products which does not seem to be a matter of irrational consumer behaviour. "Made in Italy" is confirmed as a conceptual category consolidated in the minds of consumers, since there is clear recognition of these products in terms of qualitative characterization. These and other results of the research (which need to be confirmed and extended with further empirical investigations) should prove relevant both to the literature and as indications for public policies and the strategies of companies operating in the sectors examined. For the literature this research can be useful because there is no complete overview of quantitative data on the premium price. It can also serve for public policies because quantification of the premium price can influence the choices and strategies of companies. This study shows a significant willingness to pay a premium price for the three sectors analyzed, although the premium price is not homogeneous: while the measures range mostly between 10 and $30 \%$, higher values appear for products in the food sector.
\end{abstract}

Keywords: Made in Italy, willingness to pay, consumer behaviour, country of origin, quality, innovation.

Please cite the article as follows: Cappelli, L, D’Ascenzo, Ruggieri, R, Rossetti, F, Scalingi, A, (2019), "The attitude of consumers towards "Made in Italy" products. An empirical analysis among Italian 
customers", Management \& Marketing. Challenges for the Knowledge Society, Vol. 14, No. 1, pp. 3147. DOI: $10.2478 / \mathrm{mmcks}-2019-0003$.

\section{Introduction}

Reported in this research are the results of a survey concerning the willingness of Italian consumers to pay a "premium price", providing data on the valorisation of "Made in Italy" products and the degree of innovation attributed to them. The experimental procedures used in this work have already been used and can thus be taken as consolidated and repeatable. Also, by examining the broad context of this study, decision-maker politicians and market operators will be able to make realistic data-based predictions concerning future scenarios and the possible effects and desirability of various predictions.

Thus, the paper provides further data on consumers' behaviour and enables analysis of the impact of consumers' willingness to pay a "premium price" on their choices. The research questions addressed are: 1) Does recognition in terms of the qualitative characterization of "Made in Italy" products exist? And if so, 2) Is there a willingness to pay, in quantitative terms, a "premium price" for such products?

Discussion of the literature available on this topic is followed by presentation of the results of a sample survey conducted on two Italian cities: a metropolis and a small town. The main objective is to compare lifestyles in two different contexts that are typical of the Italian scenario.

From a theoretical standpoint, the research fills a gap in the literature. In order to answer the research questions, studies concerning "Made in Italy" are combined and extended with domains recognized in the international scientific research field. Country of origin and the other two sub-dimensions, namely country image and brand image were investigated within this context from the common viewpoint of cultural heritage. The strands mentioned above converge into a broader context concerning willingness to pay a premium price, which is the specific aim of our research, and so can be considered as a cross-topic to the literature. There are many gaps regarding the characterization and quantification of the willingness to pay for "Made in Italy" products. There is no extensive literature on the perception of the real worth of "Made in Italy", with respect to quantitative evaluation of it in terms of willingness to pay a premium price for such a class of products. For this reason, our study is based on the relationship between the propensity to buy "Made in Italy" products and consumer attitudes. The paper fills a gap in the literature, since there are few references for an understanding of the real value of "Made in Italy" expressed in terms of orientation towards "Made in Italy" products, and there are scant quantifications of the willingness to pay for "Made in Italy" products. It has emerged that there is both a robust recognition of "Made in Italy" products in terms of high-quality, and a manifest willingness to pay a price increase of 10\% to 30\% (Cappelli et al., 2017). For this reason, the objective of the present study is to expand the field survey by introducing the concept of "innovation", and seeking to verify whether, and if so to what extent, consumers perceive the innovation as an element of identification of "Made in Italy" products, in order to analyze the propensity and the consumer attitude towards such products.

The paper is divided into five sections. After the introduction, the second section offers a theoretical background of "Made in Italy" structured into main research strands such as the cultural heritage, which converge into a broader context concerning the willingness to pay a premium price. The third section explains the research method, while 
section four provides a description and discussion of the research findings. The fifth section contains the final remarks and indications for future research.

\section{Literature review}

Here we analyze the literature review of "Made in Italy", the latter being a highly complex and multi-faceted concept, as it can be defined in several ways according to different perspectives. In order to answer the research questions (Does recognition in terms of the qualitative characterization of "Made in Italy" products exist? And if so, is there a willingness to pay, in quantitative terms, a "premium price" for such products?) we follow the main lines of investigation, cultural heritage and country of origin. Two subdimensions, namely country image and brand image were examined within this context. Finally, the willingness to pay a premium price represents the specific object of our research and for this reason can be a cross-topics over the literature.

\section{Cultural heritage}

In recent decades, the importance of culture and creativity for the development of economic and social systems has grown considerably (Caves, 2000; Throsby, 2005; 2010; Towe, 2011). Several national and international research reports have shown the appreciable economic importance of the European and Italian cultural and creativity industry (Napolitano, 2015). High and growing is the value of cultural production and keen and widespread is the attention of researchers and policy makers to the connections between creativity and innovation, closely connected and strategic aspects for Italy (Caliandro and Sacco, 2011). Numerous examples attest to the considerable economic added value to creativity and its cultural components, among which design is certainly the most significant. Industrial design, fashion, handicrafts and the food industry (main sectors of "Made in Italy") are based on historical experience, on knowledge gathered and acquired in particular areas and over history (Napolitano and Marino, 2013). For Italy culture and creativity represent tools for the success of territories and companies on the international markets (Napolitano, 2015). Culture and creativity are the new factors for social sustainability, for the contribution offered to the diffusion of symbolic capital and to the image of areas and companies that may find location in them and for the leading role as condition for innovation (Santagata, 2014; Della Lucia, 2014). These are critical factors for economic growth and for the international development of areas (cities and regions), of companies and of systems of companies (industrial districts and networks), because they are able to activate systematic innovation processes and promote investments in capacities and cognitive competencies, enabling the generation of districts and creative climates (Santagata, 2014). Culture and creativity are integral parts of the intangible identity of territories and the entrepreneurial fabric, as attested by the configuration of the "Made in Italy" sectors (Napolitano and Marino, 2013). Most important is the connection between culture, creativity and collective identity. The virtuous culture and creativity connection accounts for the unparalleled reputational capital built up over the years by Italian industry, based on the handcraft skills and ingenuity typical of places and populations, creativity and talent (Napolitano and Marino, 2013). It is common opinion that culture contributes to creating sustainable economic and social development, acting as a catalyser of local development, generating profitability through exploitation of resources, empowering social capital and promoting human development (Napolitano, 2015). The value of cultural capital is a systemic value: not only economic but aesthetic, spiritual, social and historical, symbolic and authentic 
(Throsby, 2005). This value is able to enhance the competitive position of the countrywide system, fuelling the labour market, retraining the most strategic segments for development and innovation (Florida, 2005) and acting as a facilitator for companies and systems of companies to enter the international markets (Sacco, 2010; Caliandro and Sacco, 2011; Cerquetti and Montella, 2012). The cultural heritage brings together resources inherited from the past which people identify as a reflection and expression of their constantly evolving values, beliefs, knowledge and traditions. It includes all aspects of the environment resulting from the interaction between people and places through time (Council of Europe, 2005). It is a distinctive factor of the image and reputation of countrywide systems and of hosted companies. According to Anholt (2007), a consistent identity and a positive reputation are the foundations of advantage not only for companies but for cities, regions and countries in global competition, capable of generating a virtuous circle of development.

The cultural heritage represents a powerful tool to communicate the identity of companies and territories and has played a vital role in the process of enrichment of the reputational heritage of countries. The large number of investigations conducted on the image of our country point to the role of tangible and intangible cultural heritage in perception of the powerful evocative force of Italian products. In spite of the importance taken on by the cultural heritage in the construction and success of the competitive identity of companies and territories, studies on country image and on country of origin effect have placed less emphasis on models to evaluate the influence of the country image, limiting the culture of evaluation to some features of the population (Varlegh, 2001; Ittersum et al., 2003). Limited, too, are the studies that have contributed to evaluation of the reputational capital of a country, highlighting the cultural component as a distinctive asset recognized by consumers (Marino and Mainolfi, 2013).

Resulting from in-depth analysis of the literature on country image (Mainolfi et al., 2015), investigation into the role of the cultural heritage image is of great importance for countrywide systems like ours, in which the image of the cultural heritage represents a tool of competitive advantage, especially on the international markets. Indeed, researches providing indications on cultural variables able to influence the perceptions and purchasing intentions of foreign consumers could offer a contribution to enhancing the "Made in" value on the international markets. The internationalization of economics and of companies has led to vigorous growth in the last few decades. In crisis periods too, export proved the lifeline of Italy's economy, maintaining the competitiveness of several companies, mainly small and medium (SME), which could only obtain limited results on the national market coming with the current competition mechanisms (Matarazzo, 2012). The Italian economic system is rich in examples of businesses that have based their strategies on the exploitation of material and immaterial elements that form Italy's cultural heritage country and represent a major component of "Made in Italy" (Plechero and Rullani, 2007). The economic and managerial literature has frequently evidenced that the cultural heritage is an important tool for the sustainability and success of companies, affecting value creation and economic advantage (Cerquetti and Montella, 2012). The cultural heritage is seen as a production value (Montella, 2009) because it assumes an active role in the production process of a company, increasing the value of products (Golinelli, 2012). Thus, the cultural heritage also has a distinctive role in defining the competitive identity of the country in the international framework (Anholt, 2007). This becomes a real production factor for "Made in Italy" companies (Cerquetti and Montella, 2012), based on the heritage of scarce, inimitable and valuable resources that can hardly 
be reproduced elsewhere. The cultural legacy of a country influences the whole creative ecosystem, both fuelling the capacity to produce cultural contents and providing incentives that support the more profitable cultural and creative industry (Throsby, 2008). For Italy, thinking about the economic relevance of cultural heritage has important implications: it highlights the fact that culture is relevant because it provides knowledge such as handcraft know-how or creative capacity, two important competitive drivers of many "Made in Italy" companies (Bettiol and Micelli, 2005). In this perspective, the value of "Made in Italy" has recently been associated with the role of manufacturing and design culture and the capacity to bring out the value of this dimension. "Made in Italy" is traditionally characterised by the creation of quality products, supported by sophisticated design and obtained thanks to the presence of manufacturing competencies typical of an industrial system made up of small companies and handcraft workshops. The growing distance between project and production place resulting from the internationalization of production and the opening of new markets has compromised the interaction that has traditionally characterized relations between designer and company. In the last few years, some authors have broken down the country of origin effect into different dimensions, showing how each may produce different effects on consumers' qualitative perceptions during the process of evaluation of alternatives. Dimensions like country of assembly, country of brand, country of manufacture and country of design have been defined. The industrial districts have played an important role in the national and international success of Italian design (Maffei and Simonelli, 2002). The networks of small and medium enterprises succeeded in benefiting from the interaction between handcraft production skills (quality production) and aesthetic flair (Chiarvesio et al., 2013). The combination of production skills and creativity has transformed design into a widespread trend in the Italian industrial system. This new conformation in which design plays a major role places a series of activities at the centre of production: product innovation, mainly, because design has become a crucial part of the rapport a company creates with its customers; in comparison to the processes of value generation, manufacturing is increasing in importance, understood as expression of skills and knowledge accumulated by people and companies and constantly aiming to guarantee the quality of products, to understand form and design with respect to technical and consumption needs, and to transmit the history and culture of company and product (Bettiol and Di Maria, 2012).

\section{Country of origin}

Over the last few years, a number of authors have divided the country of origin (COO) into sub-dimensions, showing how each of them can have different effects on consumer qualifications during the process of evaluating alternatives. There are distinct dimensions such as the country image and the brand image. The country of origin (i.e., COO) is the country of manufacture, production, or growth a product comes from. Various studies investigate the relationship between consumer behaviour and the "Made in" products, analyzing three dimensions: the affective component, the normative component and the cognitive component. In the affective component, the COO is related to a set of factors including the consumer's emotions and sensations. The normative component concerns adherence to a product's legislative standards, with particular reference to the food product sector. The cognitive approach, which assumes that consumers are rational, investigates the relationship with the willingness to pay a premium price.

Italy's country image is inevitably compared with the characteristics of the production related to "Made in Italy" focused on four macro-sectors of manufacturing 
excellence, namely the fashion system, food and beverage, home furnishings and mechanical automation (Becattini, 2000). Close to these macro-sectors, there are other high-tech areas and the Italian tourist system, focused on the environment, art, architecture and hospitality (Fortis, 2005). There are products considered Made in Italy "excellences", such as pasta, pizza and wine, protected by the Italian Institute for the Protection of Producers that sets the methods and raw materials to be used to be recognized as true products made in Italy (Toti, 2017).

However, the concept embraces various sectors, and not just food and wine.

In the fashion industry, for example, made in Italy is a symbol of elegance and style and the products are exported all over the world (Talamo, 2016).

Researches on the image of the "Made in Italy" brand have demonstrated the real significance of the brand image, placing it in the top position for brand awareness in most countries (Cappelli et. al, 2017). The "Made in Italy" brand evokes in the consumers' mind a positive attribute characterizing the image of Italy as a country. The consumer's perceptions include elements of attention such as perception (image, reputation, quality) and related behaviours (the willingness to pay a premium price).

The Made in Italy concept represents a real set of values (Mortara and Fragapane 2016). It is a trademark of origin, thanks to which the consumer is able to distinguish between national goods and imported goods (Toti, 2017).

The consumer's sense of affinity with the "Made in" of a product could have an effect on willingness to pay (Bernard and Zarrouk-Karoui, 2014). Willingness to pay is defined as the attention or perception of consumers towards the purchase of a product related to the psychological inclination to pay a premium price for a "Made in" or for a specific brand product. The consumers' willingness to pay is higher when the COO of a branded product recalls a positive country image (Koschate-Fischer et al., 2012). Thus, the consumers of a "Made in" product are willing to pay a premium price (Steenkamp et al., 2002). The consumer's willingness to pay depends on the role of the "Made in Italy" product value in evaluation. Consumers set their purchasing processes relating to assessment of country of origin, country image and brand image expressed by a directly proportional relationship with their purchasing power (Cappelli et al., 2016).

There are various studies on the willingness to pay a premium price for certain products in the literature.

For example, a recent study focuses on green products, demonstrating in that specific case how crucial the environmental apprehension of consumers is (Biswas and Roy, 2016).

Another study on willingness to pay (WTP) shows consumers' willingness to pay a premium price of $20 \%$ on organic salmon in Danish retail sale (Ankamah-Yeboah et al., 2016)

Furthermore, a study on Italian wine showed the willingness of Russian consumers to pay a premium price on Italian red wines (mainly Piedmontese and Tuscan wines) and IGT and IGP wines (Galati et al., 2017).

A recent study on secondary wood productions investigates the WTP for Italian and certified wood (Paletto and Notaro, 2018).

Our study, contributing to the aforementioned literature, seeks new evidence on the presence and quantification of WTP in certain sectors, with the focus on "Made in Italy" products in the sectors: Food and Beverage, Fashion and Accessories, Mechanical and Technology, including data on the amount of premium price resulting from the analysis. 


\section{Research method}

As empirical investigation tool, namely a questionnaire, was used to ascertain the kind of propensity towards the "Made in Italy" product and to what extent consumers' willingness to pay is based on a rational or emotional choice. Descriptive analysis was performed to analyze the willingness to pay for "Made in Italy" products, quantify the amount of the premium price, profile consumers' behaviour and describe the sociodemographic characteristics of the sample collected.

From an empirical standpoint, the paper addressed a broad spectrum of Italian companies operating in Italy's three traditional areas - food, fashion and mechanical automation - to investigate whether and if so to what extent the consumer is willing to pay a premium price for "Made in Italy" products, thereby enhancing the scope to identify the best strategies and incentives to make more of the country's productions through appropriate investments. Furthermore, the study aims to identify which "Made in Italy" production areas are more competitive for companies, in terms of recognition of a "premium price" and goes on evaluating the behaviour of firms in terms of allocation for their manufacture.

The survey involved a total of 315 Italian consumers. The questionnaire (specially constructed for this survey) was distributed on paper, to be independently filled in by the respondent and returned. Before the survey, all the items were proofread and tested for comprehension and validity, using a small-scale face-to-face pilot to fine-tune the questions measuring respondents' propensity to pay and their attitude towards "Made in Italy".

Only Italian citizens were selected, using a sampling plan stratified according to five variables: gender (male, female), age group (18-24; 25-34; 35-44; 45-54; over 55), education (up to high school, diploma, degree and higher), profession (student, unemployed, employed, entrepreneur, retiree) and income (up to $€ 18,000$; $€ 19,000$ 36,000; $€ 37,000-60,000 ; € 61,000$ and higher). 157 interviews were conducted in Cassino and 158 in Rome. The decision to consider different demographic dimension centres was made to consider the possible effect of local lifestyle both in nonmetropolitan urban areas. The questionnaire was conducted with direct interviews. Particular attention was devoted to understanding the tangible (material, form, etc.) and intangible (aesthetics, style, image, brand, etc.) characteristics of the products associated with "Made in Italy" that affect purchase. Data collection was performed using a semistructured questionnaire consisting of four sections. The first section concerns Knowledge of the Phenomenon. It associates three attributes and three brands relating to "Made in Italy" products to ascertain whether there is recognition in terms of "Made in Italy" product quality. Section 2, the willingness to pay a premium price for "Made in Italy" products, aims to quantify in percentage terms the amount that consumers would be willing to spend, focusing on three commodity sectors: food and beverage, fashion and accessories, and mechanical and technology. The third section, attitude towards "Made in Italy", applies measurement through two Likert-type rating scales (from strongly agree to strongly disagree) of the attitude towards "Made in Italy" and consumption. The last section is reserved for personal data, including the socio-demographic characteristics of the respondents.

\section{Results and discussion}

We now come to the results of the survey. Three sectors are analysed: food and beverage, fashion and accessories, mechanical and technology. The methodology used aimed to 
identify in quantitative terms the premium price that consumers are willing to pay for certain "Made in Italy" products.

Sample profile

Table 1 summarizes the sample profile. Just over half of the respondents are male (51\%) and the frequency is homogeneously distributed in the age groups considered. They have a high school diploma or attended University (Degree/Master/PhD), only $0.3 \%$ having no formal education. About $46 \%$ are employed in public or private offices, and $22 \%$ are selfemployed professionals. $80 \%$ of the Italian respondents earn up to 36,000 Euro, while only $20 \%$ of the interviewees have an income that falls within the "medium-high" income category.

Table 1. Sociodemographic composition of the sample

\begin{tabular}{|c|c|c|c|}
\hline & & Frequency & Frequency (\%) \\
\hline \multirow[t]{2}{*}{ Gender } & Male & 160 & 51 \\
\hline & Female & 155 & 49 \\
\hline \multirow[t]{4}{*}{ Age } & $18-25$ & 71 & 22 \\
\hline & $26-38$ & 89 & 28 \\
\hline & $39-52$ & 80 & 25 \\
\hline & 53-99 & 75 & 24 \\
\hline \multirow[t]{5}{*}{ Level of education } & None & 1 & - \\
\hline & Primary school & 4 & 1 \\
\hline & Secondary school & 97 & 31 \\
\hline & High school & 109 & 35 \\
\hline & Degree/Master/PhD & 104 & 33 \\
\hline \multirow[t]{5}{*}{ Profession } & Student & 53 & 17 \\
\hline & Unemployed & 38 & 12 \\
\hline & Employed & 146 & 46 \\
\hline & Entrepreneur & 68 & 22 \\
\hline & Retiree & 10 & 3 \\
\hline \multirow[t]{4}{*}{ Income $^{1}$ bracket $^{2}$} & $<€ 18 \mathrm{k}$ & 92 & 38 \\
\hline & from $€ 19 \mathrm{k}$ to $€ 36 \mathrm{k}$ & 102 & 42 \\
\hline & from $€ 37 \mathrm{k}$ to $€ 60 \mathrm{k}$ & 42 & 17 \\
\hline & $>€ 61 \mathrm{k}$ & 8 & 3 \\
\hline
\end{tabular}

The survey

The Italian respondents' opinions on the "Made in Italy" image was collected through two questions with open answers. The first question asks respondents to indicate the first three adjectives associated with "Made in Italy". As shown in Figure 1a, the aspects are associated with the products' characteristics (quality, expensive, reliable). The second question asks respondents to specify the first three brands that come to mind representing "Made in Italy" products. The results are split into two sectors (automotive and food) which involve Italy's highest exports around the world (Figure 1b). The bestknown brands are Ferrari, Barilla and Fiat. Regarding Fiat, it is worth noting that it has changed its brand name to FCA, Fiat Chrysler Automobiles, yet consumers still link it with

\footnotetext{
${ }^{1}$ Here we have 244 respondents out of the 315 : about $23 \%$ of the interviewees preferred not to declare their income.

${ }^{2}$ Income brackets as per Italian Indicator of Equivalent Economic Situation (ISEE).
} 
the old brand name. Thus, considering the other brands indicated by respondents, the "Made in Italy" product areas that come to the fore for consumers are: Food \& Beverage (40\%), Mechanical \& Technology (30\%), and Fashion \& Accessories (30\%).

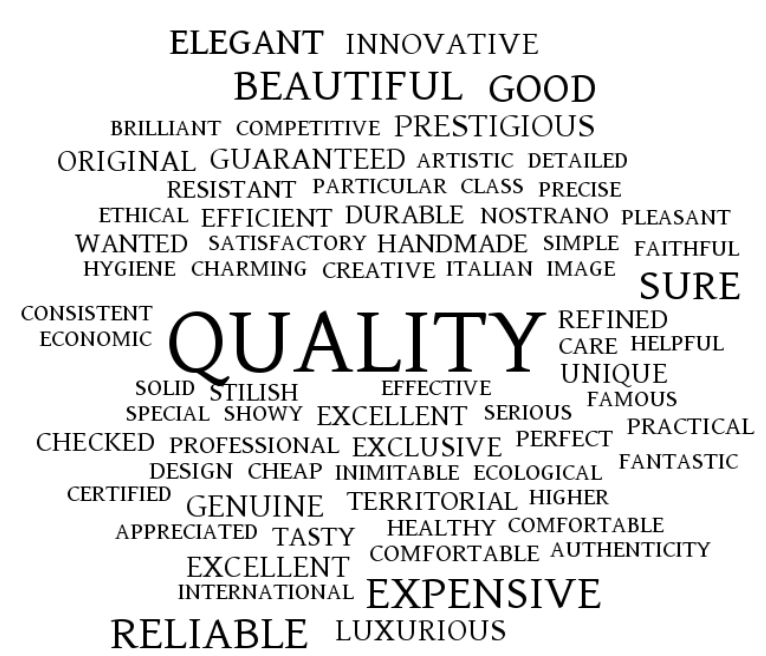

(a)

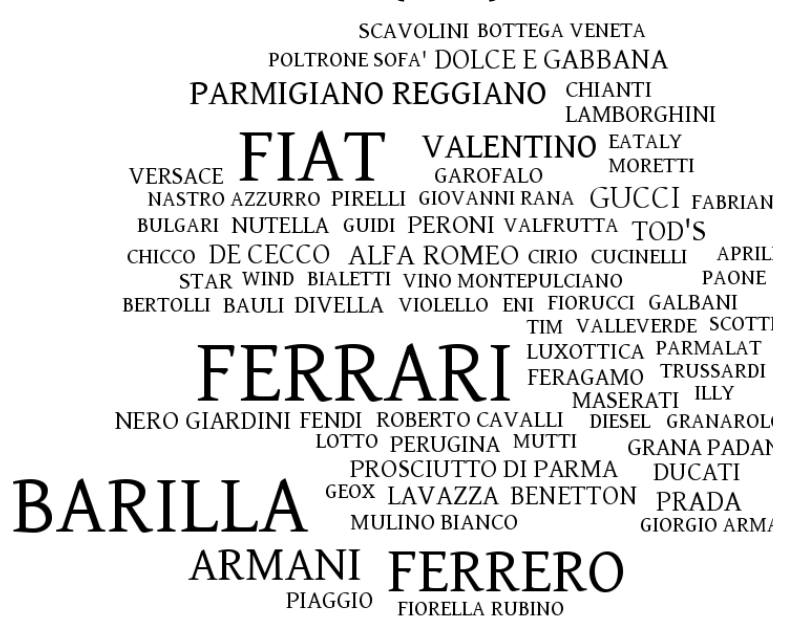

(b)

Figure 1. Word Cloud: perception of the characteristics of "Made in Italy" and principal brands. (a) The top 3 adjectives that come to mind when talking about "Made in Italy" where quality is the most important (b) The top 3 brands that come to mind when talking about "Made in Italy".

Source: Authors' own research.

The willingness to pay a premium price

Quality of service is of fundamental importance for several firms as customers expect high-quality services and are willing to pay a premium for them (Dong and Park, 2007). But customers also want high-quality products. Hence, in the second part of the survey (behaviours towards "Made in Italy"), we asked consumers to indicate the amount of premium price they would pay for such products in order to ascertain whether they would be willing to pay for a "Made in Italy" product and, if so, how much more. Figure 2 shows the results divided by production area. In Food \& Beverage (Fig. 2a), about 13\% of the respondents are willing to pay an additional price of more than 50\%, while $34 \%$ quantified a premium price from $30 \%$ to $50 \%$. About $50 \%$ are willing to pay a premium price between $10 \%$ to $30 \%$ for a "Made in Italy" fashion product (Fig. 2b), while in the Mechanical \& Technology production sector (Fig. 2c) about $40 \%$ are willing to pay an additional price of no more than $10 \%$. 


\section{Food \& Beverage}

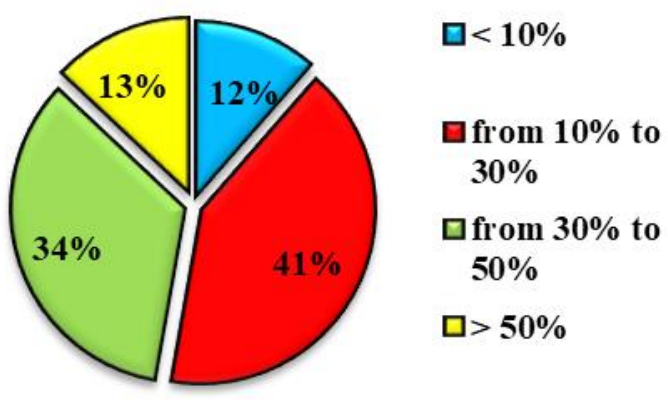

\section{Fashion \& Accessories}

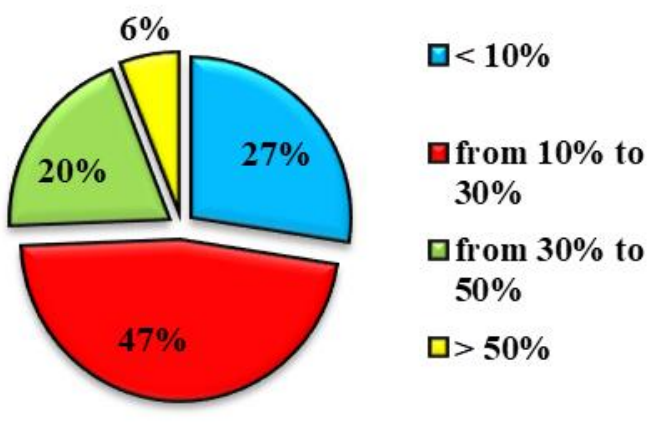

\section{Mechanical \&Technology}

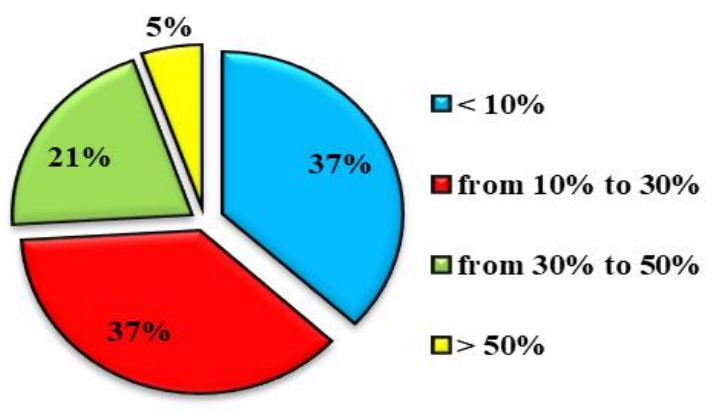

Figure 2. Product areas: Quantification of increase that the Italian consumer would be willing to pay for a "Made in Italy" product. (a) Willingness to pay a "premium price" for products in the food sector; (b) Willingness to pay a "premium price" for products in the clothing industry; (c) Willingness to pay a "premium price" for products in the mechanical/technological sector.

Source: Authors' own research.

The premium price; how much more

Here we examine the relationship between the premium price and some sociodemographical variables (gender, age, education, profession and income). Focusing on the lowest (from $<10 \%$ to $30 \%$ ) and highest percentage (from $30 \%$ to $>50 \%$ ) of willingness 
to pay a premium price, in the distribution by gender (Tab. 2), in general women are willing to pay more for a "Made in Italy" product. In particular, the highest premium price was observed in the Food \& Beverage area (about 54\%), while about 80\% of men are willing to pay less than women for a "Made in Italy" fashion product.

Table 2. The amount of premium price: distribution by gender

\begin{tabular}{|l|l|l|l|l|}
\hline \multicolumn{5}{|c|}{ Food \& Beverage } \\
\hline & $<\mathbf{1 0 \%}$ & $\mathbf{1 0 - 3 0 \%}$ & $\mathbf{3 0 - 5 0 \%}$ & $>\mathbf{5 0 \%}$ \\
\hline Female & $11 \%$ & $35 \%$ & $38 \%$ & $16 \%$ \\
\hline Male & $12 \%$ & $47 \%$ & $31 \%$ & $10 \%$ \\
\hline
\end{tabular}

\begin{tabular}{|l|l|l|l|l|}
\hline \multicolumn{5}{|c|}{ Fashion \& Accessories } \\
\hline & $<\mathbf{1 0} \%$ & $\mathbf{1 0 - 3 0 \%}$ & $\mathbf{3 0 - 5 0 \%}$ & $>\mathbf{5 0 \%}$ \\
\hline Female & $25 \%$ & $44 \%$ & $25 \%$ & $6 \%$ \\
\hline Male & $28 \%$ & $52 \%$ & $16 \%$ & $5 \%$ \\
\hline
\end{tabular}

\begin{tabular}{|l|l|l|l|l|}
\hline \multicolumn{5}{|c|}{ Mechanical \& Technology } \\
\hline & $<\mathbf{1 0} \%$ & $\mathbf{1 0 - 3 0 \%}$ & $\mathbf{3 0 - 5 0 \%}$ & $\mathbf{> 5 0 \%}$ \\
\hline Female & $36 \%$ & $37 \%$ & $22 \%$ & $5 \%$ \\
\hline Male & $38 \%$ & $38 \%$ & $18 \%$ & $6 \%$ \\
\hline
\end{tabular}

With respect to the classification by age (Tab. 3), the millennials (18-25 years) seem more willing to pay for a food and mechanical-technological product and less for a fashion product labelled "Made in Italy" (about 80\%), while people born before 1963 (>53 years) have the highest premium price in the Fashion \& Accessories area (about 32\%). By contrast, adding two age classes, people between 26 and 52 years show the lowest willingness to pay a premium price for a "Made in Italy" fashion product (about 75\% both age classes).

Table 3. The amount of premium price: distribution by age

\begin{tabular}{|l|l|l|l|l|}
\hline \multicolumn{5}{|c|}{ Food \& Beverage } \\
\hline Years & $<\mathbf{1 0} \%$ & $\mathbf{1 0 - 3 0} \%$ & $\mathbf{3 0 - 5 0 \%}$ & $\mathbf{5 0 \%}$ \\
\hline $\mathbf{1 8 - 2 5}$ & $10 \%$ & $34 \%$ & $45 \%$ & $11 \%$ \\
\hline $\mathbf{2 6 - 3 8}$ & $10 \%$ & $42 \%$ & $33 \%$ & $16 \%$ \\
\hline $\mathbf{3 9 - 5 2}$ & $18 \%$ & $40 \%$ & $29 \%$ & $14 \%$ \\
\hline$>\mathbf{5 3}$ & $8 \%$ & $48 \%$ & $33 \%$ & $11 \%$ \\
\hline
\end{tabular}

\begin{tabular}{|l|l|l|l|l|}
\hline \multicolumn{5}{|c|}{ Fashion \& Accessories } \\
\hline Years & $<\mathbf{1 0 \%}$ & $\mathbf{1 0 - 3 0 \%}$ & $\mathbf{3 0 - 5 0 \%}$ & $\mathbf{5 0 \%}$ \\
\hline $\mathbf{1 8 - 2 5}$ & $23 \%$ & $58 \%$ & $15 \%$ & $4 \%$ \\
\hline $\mathbf{2 6 - 3 8}$ & $27 \%$ & $46 \%$ & $24 \%$ & $3 \%$ \\
\hline $\mathbf{3 9 - 5 2}$ & $33 \%$ & $43 \%$ & $15 \%$ & $10 \%$ \\
\hline$>\mathbf{5 3}$ & $21 \%$ & $47 \%$ & $25 \%$ & $7 \%$ \\
\hline
\end{tabular}

\begin{tabular}{|l|l|l|l|l|}
\hline \multicolumn{5}{|c|}{ Mechanical \& Technology } \\
\hline Years & $<\mathbf{1 0 \%}$ & $\mathbf{1 0 - 3 0 \%}$ & $\mathbf{3 0 - 5 0 \%}$ & $>\mathbf{5 0 \%}$ \\
\hline $\mathbf{1 8 - 2 5}$ & $38 \%$ & $37 \%$ & $21 \%$ & $4 \%$ \\
\hline $\mathbf{2 6 - 3 8}$ & $30 \%$ & $42 \%$ & $24 \%$ & $4 \%$ \\
\hline $\mathbf{3 9 - 5 2}$ & $34 \%$ & $40 \%$ & $19 \%$ & $8 \%$ \\
\hline $\mathbf{5 3}$ & $47 \%$ & $29 \%$ & $19 \%$ & $5 \%$ \\
\hline
\end{tabular}

Source: Authors' own research. 
Regarding distribution by educational level, a greater variance emerges in the relationship between the willingness to pay and the level of education (separated into two categories: primary school and degree/master/PhD) (Tab. 4). In all three productive sectors considered, there is a directly proportional relationship on the split "from $<10 \%$ to $30 \%$ " and "from $30 \%$ to $>50 \%$ ", depending on the level of education (respectively, an average of $41 \%$ of those with a more modest educational background against an average of $92 \%$ in the case of the more highly educated).

Table 4. The amount of premium price: distribution by education level

\begin{tabular}{|l|l|l|l|l|}
\hline \multicolumn{5}{|c|}{ Food \& Beverage } \\
\hline & $<\mathbf{1 0} \%$ & $\mathbf{1 0 - 3 0 \%}$ & $\mathbf{3 0 - 5 0 \%}$ & $\mathbf{5 0 \%}$ \\
\hline Primary School & $25 \%$ & $50 \%$ & $0 \%$ & $25 \%$ \\
\hline Secondary School & $18 \%$ & $51 \%$ & $26 \%$ & $6 \%$ \\
\hline High School & $9 \%$ & $39 \%$ & $37 \%$ & $15 \%$ \\
\hline Degree/Master/PhD & $10 \%$ & $33 \%$ & $42 \%$ & $15 \%$ \\
\hline
\end{tabular}

\begin{tabular}{|l|l|l|l|l|}
\hline \multicolumn{5}{|c|}{ Fashion \& Accessories } \\
\hline & $<\mathbf{1 0} \%$ & $\mathbf{1 0 - 3 0 \%}$ & $\mathbf{3 0 - 5 0 \%}$ & $\mathbf{5 0 \%}$ \\
\hline Primary School & $100 \%$ & $0 \%$ & $0 \%$ & $0 \%$ \\
\hline Secondary School & $35 \%$ & $45 \%$ & $15 \%$ & $4 \%$ \\
\hline High School & $23 \%$ & $50 \%$ & $19 \%$ & $7 \%$ \\
\hline Degree/Master/PhD & $17 \%$ & $50 \%$ & $26 \%$ & $7 \%$ \\
\hline
\end{tabular}

\begin{tabular}{|l|l|l|l|l|}
\hline \multicolumn{5}{|c|}{ Mechanical \& Technology } \\
\hline & $\mathbf{1 0 \%}$ & $\mathbf{1 0 - 3 0 \%}$ & $\mathbf{3 0 - 5 0 \%}$ & $\mathbf{5 0 \%}$ \\
\hline Primary School & $100 \%$ & $0 \%$ & $0 \%$ & $0 \%$ \\
\hline Secondary School & $45 \%$ & $27 \%$ & $21 \%$ & $7 \%$ \\
\hline High School & $37 \%$ & $45 \%$ & $14 \%$ & $4 \%$ \\
\hline Degree/Master/PhD & $26 \%$ & $40 \%$ & $29 \%$ & $5 \%$ \\
\hline
\end{tabular}

Source: Authors' own research.

In the distribution by profession (Tab. 5), the lowest willingness to pay is shown by retirees in the food (80\%) and mechanical/technology $(90 \%)$ sectors, and the unemployed for Fashion \& Accessories (82\%), while students, retirees and those employed are willing to pay more for "Made in Italy" products in the food (53\%), fashion $(40 \%)$ and the mechanical/technology (27\%) sectors respectively.

Table 5. The amount of premium price: distribution by profession

\begin{tabular}{|l|l|l|l|l|}
\hline \multicolumn{5}{|c|}{ Food \& Beverage } \\
\hline & $<\mathbf{1 0 \%}$ & $\mathbf{1 0 - 3 0 \%}$ & $\mathbf{3 0 - 5 0 \%}$ & $>\mathbf{5 0 \%}$ \\
\hline Unemployed & $26 \%$ & $34 \%$ & $29 \%$ & $11 \%$ \\
\hline Student & $8 \%$ & $40 \%$ & $43 \%$ & $9 \%$ \\
\hline Retiree & $20 \%$ & $60 \%$ & $10 \%$ & $10 \%$ \\
\hline Employed & $11 \%$ & $42 \%$ & $35 \%$ & $12 \%$ \\
\hline Entrepreneur & $21 \%$ & $44 \%$ & $25 \%$ & $10 \%$ \\
\hline
\end{tabular}

\begin{tabular}{|l|l|l|l|l|}
\hline \multicolumn{5}{|c|}{ Fashion \& Accessories } \\
\hline & $<\mathbf{1 0} \%$ & $\mathbf{1 0 - 3 0 \%}$ & $\mathbf{3 0 - 5 0 \%}$ & $>\mathbf{5 0 \%}$ \\
\hline Unemployed & $32 \%$ & $50 \%$ & $18 \%$ & $0 \%$ \\
\hline Student & $23 \%$ & $53 \%$ & $19 \%$ & $6 \%$ \\
\hline Retiree & $40 \%$ & $20 \%$ & $20 \%$ & $20 \%$ \\
\hline Employed & $28 \%$ & $46 \%$ & $20 \%$ & $6 \%$ \\
\hline Entrepreneur & $28 \%$ & $50 \%$ & $13 \%$ & $9 \%$ \\
\hline
\end{tabular}




\begin{tabular}{|l|l|l|l|l|}
\hline \multicolumn{5}{|c|}{ Mechanical \& Technology } \\
\hline & $<\mathbf{1 0} \%$ & $\mathbf{1 0 - 3 0 \%}$ & $\mathbf{3 0 - 5 0 \%}$ & $>\mathbf{5 0 \%}$ \\
\hline Unemployed & $39 \%$ & $39 \%$ & $18 \%$ & $3 \%$ \\
\hline Student & $43 \%$ & $36 \%$ & $17 \%$ & $4 \%$ \\
\hline Retiree & $60 \%$ & $30 \%$ & $10 \%$ & $0 \%$ \\
\hline Employed & $38 \%$ & $35 \%$ & $22 \%$ & $5 \%$ \\
\hline Entrepreneur & $44 \%$ & $35 \%$ & $16 \%$ & $4 \%$ \\
\hline
\end{tabular}

Source: Authors' own research.

Lastly, Tab. 6 shows a direct proportionality emerging from the data between the level of Italian respondents' income and the amount of the premium price they would be willing to pay. Indeed, in all three areas considered, the lowest income bracket corresponds to the lowest premium price, and the highest income bracket corresponds to the highest premium price. Half of the respondents belonging to the second income bracket are willing to pay more for a "Made in Italy" food product, and for the third income bracket analyzed in the same product area, the amount of premium price is about $60 \%$.

Table 6. The amount of premium price: distribution by income

\begin{tabular}{|c|c|c|c|c|}
\hline \multicolumn{5}{|c|}{ Food \& Beverage } \\
\hline & $<10 \%$ & $10-30 \%$ & $30-50 \%$ & $>50 \%$ \\
\hline$<€ 18,000$ & $12 \%$ & $42 \%$ & $34 \%$ & $12 \%$ \\
\hline $\begin{array}{l}€ 19,000- \\
€ 36,000\end{array}$ & $9 \%$ & $41 \%$ & $40 \%$ & $10 \%$ \\
\hline $\begin{array}{l}€ 37,000- \\
€ 60,000\end{array}$ & $17 \%$ & $45 \%$ & $21 \%$ & $17 \%$ \\
\hline$>€ 61,000$ & $0 \%$ & $50 \%$ & $38 \%$ & $13 \%$ \\
\hline
\end{tabular}

\begin{tabular}{|c|c|c|c|c|}
\hline \multicolumn{5}{|c|}{ Fashion \& Accessories } \\
\hline & $<10 \%$ & $10-30 \%$ & $30-50 \%$ & $>50 \%$ \\
\hline$<€ 18,000$ & $29 \%$ & $50 \%$ & $16 \%$ & $4 \%$ \\
\hline $\begin{array}{l}€ 19,000- \\
€ 36,000\end{array}$ & $25 \%$ & $52 \%$ & $18 \%$ & $6 \%$ \\
\hline $\begin{array}{l}€ 37,000 \\
€ 60,000\end{array}$ & $26 \%$ & $40 \%$ & $24 \%$ & $10 \%$ \\
\hline$>€ 61,000$ & $25 \%$ & $38 \%$ & $13 \%$ & $25 \%$ \\
\hline
\end{tabular}

\begin{tabular}{|c|c|c|c|c|}
\hline \multicolumn{5}{|c|}{ Mechanical \& Technology } \\
\hline & $<10 \%$ & $10-30 \%$ & $30-50 \%$ & $>50 \%$ \\
\hline$<€ 18,000$ & $40 \%$ & $39 \%$ & $14 \%$ & $7 \%$ \\
\hline $\begin{array}{l}€ 19,000- \\
€ 36,000\end{array}$ & $39 \%$ & $40 \%$ & $18 \%$ & $3 \%$ \\
\hline $\begin{array}{l}€ 37,000- \\
€ 60,000\end{array}$ & $36 \%$ & $33 \%$ & $24 \%$ & $7 \%$ \\
\hline$>€ 61,000$ & $13 \%$ & $13 \%$ & $63 \%$ & $13 \%$ \\
\hline
\end{tabular}

Source: Authors' own research.

With respect to the image of "Made in Italy" perceived by interviewees, two blocks of statements composed of six and seven items were constructed (Figure 3). The first was to indicate the propensity towards purchase of "Made in Italy" products, while the second was to gauge the level of consumer rationality.

The distribution of respondents over the various items of the two categories is shown in Figures 3a and Figure 3b. In the separate items related to the level of consumer rationality, the respondents agree or disagree with a given statement. In the case of agreement, the item "price comparison" accounts for about $90 \%$ of respondents, while for disagreement the item "flyer" sees $74 \%$ of respondents expressing disagreement with the 
statement "I do not consult bid fliers". The statement "I feel gratified when I buy a "Made in Italy" product results in $82 \%$ agreement among respondents and, consistently, the reverse coded affirmation "It is a myth created by the Italians and is not greatly appreciated abroad" results in $84 \%$ of samples in disagreement (Figure 3b).

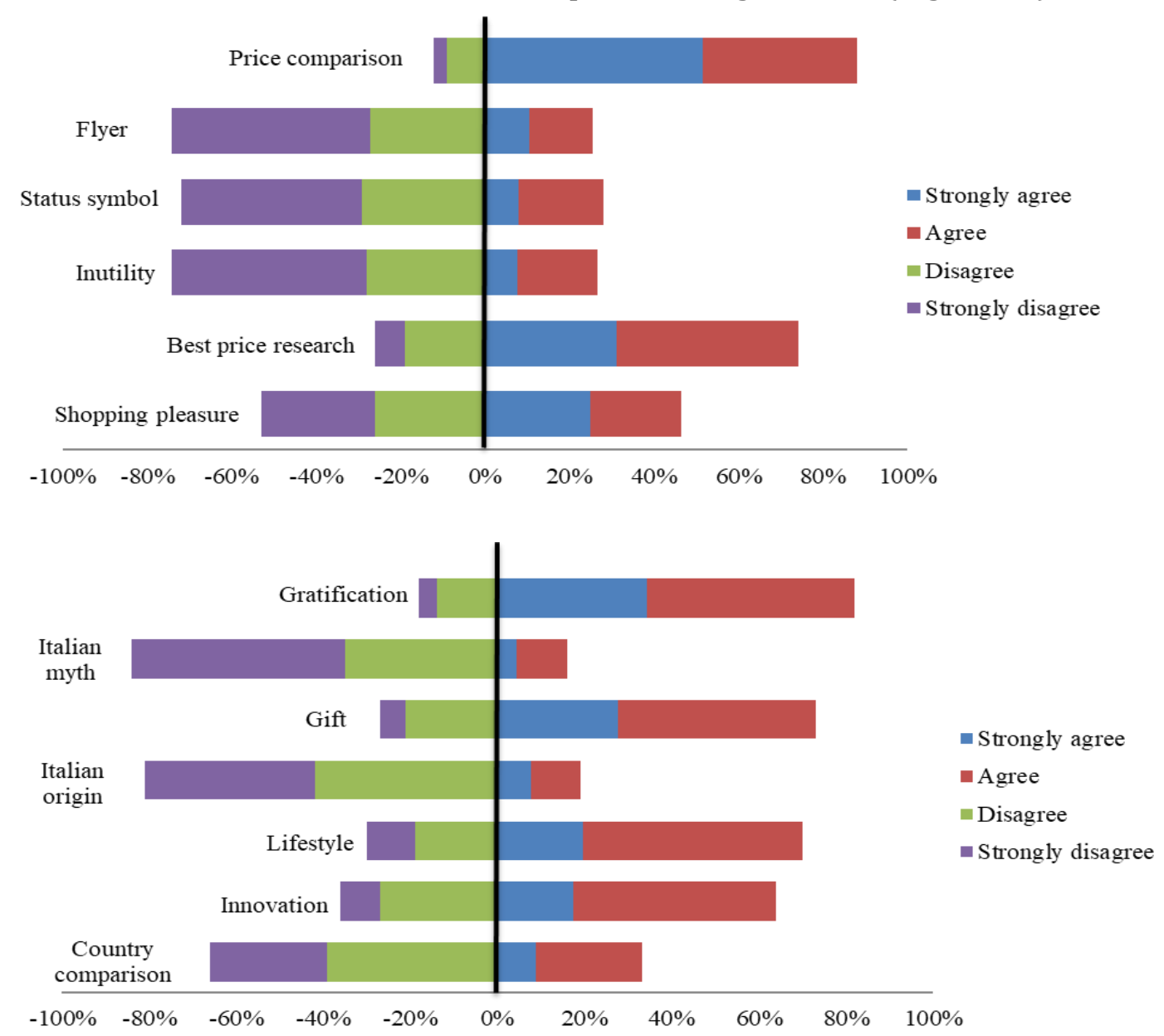

Figure 3. a) Respondents according to the level of agreement with the items relating to the propensity towards purchase of "Made in Italy" products; b) Respondents according to the level of agreement with the items on consumer rationality.

Source: Authors' own research.

The characteristics that consumers associate with "Made in Italy" products were investigated detecting willingness/unwillingness to pay and quantifying the amount of the "premium price" that consumers are willing to pay for such products. A robust recognition for "Made in Italy" products has come to light (Cappelli et al., 2016). For this reason, the aim of this study has been to expand the field survey by introducing the concept of "innovation", and attempting to verify whether, and if so to what extent, consumers perceive "Made in Italy" product innovation as an identification element.

About those in agreement, the statement "Made in Italy products are innovative" finds agreement with over $60 \%$ of Italian respondents, while for those who disagreed, the statement "German products are more innovative than Italian products" is approved by $66 \%$ of respondents. 
The empirical survey confirms the presence of a propensity towards purchase of "Made in Italy" products, which does not seem to be supported by an irrational consumer attitude.

\section{Conclusions}

The study offers food for thought and material for discussion. From a theoretical standpoint, this research can help fill the existing gap in the literature. We have also extended our study to some domains recognized in the international scientific research field, such as country of origin, origin brand, and country image from the common viewpoint of willingness to pay a premium price.

The empirical investigation examined the existence of a "premium price" recognized by consumers in relation to the "Made in Italy" product, seeking to quantify this result in terms of price ranges and for different sectors.

In conclusion, we have replied to the research questions addressed: "Made in Italy" is well established as a conceptual category in the minds of consumers since there is recognition of such products in terms of product characterization with the adjective "quality".

There is a significant willingness to pay a premium price, as declared by consumers for the three sectors analyzed (food, fashion and mechanical automation). The "premium price" is not homogeneously identified for the various product sectors analysed, although for all the most commonly encountered sectors, the value ranges between $10-30 \%$.

Rational consumer choice is not only based on the emotional element, but on a cognitive approach. We can see a strong propensity towards purchase of "Made in Italy" products, the identification of "Made in Italy" products as being innovative and recognition of "Made in Italy" products as innovative when compared to another country's (Germany).

This empirical investigation proves that both qualitatively and quantitatively "Made in Italy" has considerable value. The results of our research can have practical and managerial implications. In fact, the presence of a quantitatively demonstrated "Made in Italy" value may prove useful for the defence of "Made in Italy" productions

Moreover, for companies the identification of a quantitative value of "Made in Italy" can be useful for price and location strategies.

The main limitations to this study lie in the geographical aspect (although sampling has been made to represent the entire population, the survey was conducted in only two towns, Rome and Cassino), the correct legal/regulatory definition of "Made in Italy", which is not investigated, while future improvements may be achieved in field regarding analysis of the questionnaire's reliability. Looking ahead, the aim is to conduct an in-depth study on the relationship between identification of the "Made in Italy" brand and consumers' willingness to pay. We will study the relationship between "Made in Italy" and "willingness to pay" for specific production areas in order to identify which area of areas of "Made in Italy" are most promising for enterprises.

\section{References}

Anholt, S. (2007), Competitive identity: The new brand management for nations, cities and regions, Palgrave Macmillan, New York.

Ankamah-Yeboah, I., Nielsen, M. and Nielsen, R. (2016). Price premium of organic salmon in Danish retail sale. Ecological Economics, 122, 54-60 
Becattini, G. (2000), Dal distretto industriale allo sviluppo locale, Bollati Boringhieri, Torino.

Bernard, Y. and Zarrouk-Karoui, S. (2014). Reinforcing willingness to buy and to pay due to consumer affinity towards a foreign country. International Management Review, 10(2), 57-67

Bettiol, M., and Di Maria, E. (2012). Introduzione: oltre la dicotomia manifattura-servizi: un territorio ancora da esplorare. Economia e società regionale, 117(3), 5-11.

Bettiol, M. and Micelli, S. (2005), Design e creatività nel made in Italy. Proposte per i distretti industriali, Mondadori Bruno Ed.

Biswas, A. and Roy, M. (2016). A study of consumers' willingness to pay for green products. Journal of Advanced Management Science Vol, 4(3), 211-215

Caliandro, C. and Sacco, L. (2011), Italia reloaded. Ripartire con la cultura, Il Mulino, Bologna.

Cappelli, L., D’Ascenzo, F., Natale, L, Rossetti, F., Ruggieri, R. and Vistocco, D. (2016), "Is the Made in Italy a key to success? An empirical investigation" in: Proceedings Congresso di Scienze Merceolgiche, 2-4 March, Viterbo, Italy, 123-130.

Cappelli, L., D’Ascenzo, F., Natale, L., Rossetti, F., Ruggieri, R. and Vistocco, D. (2017) Are Consumers Willing to pay More for a "Made in" Product? An Empirical Investigation on "Made in Italy", Sustainability, 9 (4), 556.

Cappelli, L., D’Ascenzo, F., Natale, L., Rossetti, F., Ruggieri, R. and Vistocco, D. (2016), "Consumer attitude towards the products Made in Italy. An empirical investigation" in: Proceedings of the 19th QMOD-ICQSS International Conference on Quality and Service Sciences. Building a Culture for Quality, Innovation and Sustainability. 1835-1838.

Caves, R., (2000), Creative Industries: Contracts between Art and Commerce, Harvard University Press, Cambridge.

Cerquetti, M. and Montella, M., (2012), "Paesaggio e patrimonio culturale come fattori di vantaggio competitivo per le imprese di prodotti tipici della regione Marche", Proceedings of the XXIV Conference of Sinergie, Il territorio come giacimento di vitalità per l'impresa, Università del Salento, Lecce, 18-19 ottobre 2012, 549-562.

Chiarvesio, M., Di Maria, E. and Micelli, S. (2013). Sourcing from Northern and Southern Countries: The global value chain approach applied to Italian SMEs. Transition Studies Review, 20(3), 389-404.

Dong, K.Y. and Park, J.A., (2007), "Perceived service quality: Analyzing relationships among employees, customers, and financial performance", International Journal of Quality \& Reliability Management, 24(9), 908-926.

Florida, R., (2005), The flight of the creative class: the new global competition for talent, Harper Collins Publishers, New York.

Fortis, M., (2005), "Il Made in Italy tra Commercio Leale e Innovazione Industriale", In Proceedings of the II Conferenza Nazionale sul Commercio con l'Estero, Roma.

Galati, A., Crescimanno, M., Abbruzzo, A., Chironi, S. and Tinervia, S. (2017). The premium price for Italian red wines in new world wine consuming countries: the case of the Russian market. Journal of Wine Research, 28(3), 181-193.

Golinelli, G.M., (2012), Patrimonio Culturale e Creazione di Valore, CEDAM.

Ittersum, K.V., Candel, M.J.J.M. and Meulenberg, M.T.G. (2003), "The Influence of the Image of a Product's Region of Origin on Product Evaluation", Journal of Business Research, 56(3), 215-226 
Koschate-Fischer, N.; Diamantopoulos, A. and Oldenkotte, K. (2012), "Are consumers really willing to pay more for a favorable country image? A study of country-oforigin effects on willingness to pay", Journal of International Marketing, 20(1), 1941.

Maffei S. and Simonelli G., (2002), I territori del design. Made in Italy e sistemi produttivi locali, Il Sole 24-Ore, Milano.

Mainolfi, G., De Nisco, A., Marino, V. and Napolitano, M.R., (2015), "Immagine Paese e cultural heritage. Proposta e validazione di una scala di misura formativa della cultural heritage image (CHEI)", in: Proceedings of XII Convegno annuale della Società Italiana Marketing, Università degli Studi di Torino, 22-23 Ottobre.

Marino, V. and Mainolfi, G., (2013), Country Brand Management. Esperienze internazionali a confronto attraverso la ricerca qualitativa, Egea, Milano.

Matarazzo, M., (2012), Le strategie internazionali delle medie imprese. Modalità di entrata e nuovi mercati, Franco Angeli, Milano.

Montella M. (2009), Valore e valorizzazione del patrimonio culturale storico, Electa, Milano.

Mortara, A. and Fragapane, S. (2016). Moda, made in Italy e sostenibilità: un connubio possibile? (Italian). Rivista Trimestrale Di Scienza Dell'Amministrazione, (4), 1

Napolitano, M.R and Marino, V., (2016). Cultural Heritage e Made in Italy, Editoriale Scientifica. Napoli.

Napolitano, M.R. and Marino, V., (2016), “Cultural Heritage e posizionamento competitivo del made in italy nei mercati internazionali", Cultural Heritage e Made in Italy, Editoriale Scientifica, Napoli.

Napolitano, M.R., (2015), "Valore della Cultura e Cultura del Valore. Riflessioni per il futuro del Bel Paese", Il Capitale culturale, Studies on the Value of Cultural heritage, (11) 371-393.

Paletto, A. and Notaro, S. (2018). Secondary wood manufactures' willingness-to-pay for certified wood products in Italy. Forest Policy and Economics, 92, 65-72

Plechero, M. and Rullani, E., Innovare. Reinventare il made in Italy, EGEA. Milano.

Sacco, P.L. (2010), “Cultura e sviluppo locale: il distretto culturale evoluto”, Sinergie, (82), 115-119.

Santagata, W., (2014), Il governo della cultura. Promuovere sviluppo e qualità sociale, Il Mulino, Bologna.

Steenkamp, J.-B.E.M., Batra, R. and Alden, D.L. (2002), "How perceived brand globalness creates brand value", Journal of International Business Studies, 34(1), 53-65.

Talamo, G. (2016). Internazionalizzazione, backshoring e made in Italy: un'analisi del settore moda e lusso in Italia. Rivista trimestrale di Scienza dell'Amministrazione, 4, 1-12

Throsby, D., (2008), Economia e Cultura, Il Mulino, Bologna.

Throsby, D., (2010), The Economics of Cultural Policy, Cambridge University Press, Cambridge.

Toti E. (2017). Le eccellenze e la tutela del "Made in Italy." Rivista di Scienza dell'Alimentazione, 46 (3), 39-42

Towse, R., (2011), A Handbook of Cultural Economics, Edward Elgar Publishing, Northampton.

Verlegh, P.W.J., (2001). Country-of-Origin Effects on Consumer Product Evaluations. Doctoral Dissertation, Wageningen University. 